\begin{tabular}{|l|l|}
\hline $\begin{array}{l}\text { ESCOLA DE COMUNICAÇÃO, } \\
\text { ARTES E DESIGN }\end{array}$ & $\begin{array}{l}\text { mídia, cultura e tecnologia } \\
\text { Revista FAMECOS, Porto Alegre, v. 27, p. 1-11, jan.-dez. } 2020 \\
\text { PUCRS }\end{array}$ \\
\hline FAMECOS & $\begin{array}{l}\text { e-ISSN: 1980-3729 | ISSN-L: 1415-0549 } \\
\text { https://dx.doi.org/10.15448/1980-3729.2020.1.37518 }\end{array}$ \\
\hline
\end{tabular}

CINEMA

\title{
Iterações do cinema em filmes sobre jornalistas
}

\author{
Iterations of cinema in films about journalists \\ Iteraciones del cine en películas sobre periodistas
}

\author{
Thales Vilela Lelo ${ }^{1}$ \\ 0000-0002-6070-9332 \\ thales.lelo@gmail.com
}

Recebido em: 31/3/2020.

Aprovado em: 7/11/2020.

Publicado em: 7/01/2021.

\section{(c) (1)}

Artigo está licenciado sob forma de uma licença Creative Commons Atribuição 4.0 Internacional.
Resumo: O artigo questiona um filão dos estudos de cinema que reivindica que a filmografia sobre o mundo do trabalho dos jornalistas deve ser compreendida como instrumento de critica da mídia. Tomando por referências duas produções estadunidenses recentes aclamadas em festivais internacionais, Spotlight (2015) e O Abutre (2014), o texto investe em uma análise dos componentes estéticos e narrativos das obras, evidenciando a trama intertextual que elas tecem com outros filmes do gênero e como esta interlocução lhes conduz a reverberar um imaginário de idealização da imprensa liberal que fora historicamente fomentado pelo próprio cinema - e que não necessariamente traduz os dilemas que o jornalismo contemporaneamente vivencia.

Palavras-chave: Cinema. Jornalismo. Intertextualidade.

Abstract: The article questions a lode of cinema studies that reclaims that the filmography about the world of work of journalists must be apprehended as a media criticism instrument. Taking by reference two recent American productions acclaimed at international festivals, Spotlight (2015) and Nightcrawler (2014), the text invests in an analysis of the aesthetics and narrative components of this movies, highlighting the intertextual plot that they weave with other movies of this genre and how this dialogue leads them to reverberate an imaginary of idealization of liberal press that was historically fomented by own cinema - and which does not necessarily translate the dilemmas that journalism experiences nowadays.

Keywords: Cinema. Journalism. Intertextuality.

Resumen: El articulo cuestiona un filón de estudios del cine os cuales reivindican que la filmografía acerca del mundo del trabajo de los periodistas debe ser comprendida como instrumento de crítica del medios. Tomando por referencia dos producciones estadounidenses recientes aclamadas en los festivales internacionales, Spotlight (2015) y Nightcrawler (2014), el texto invierte en un análisis de los componentes estéticos y narrativos de las obras, evidenciando la trama intertextual que ellas traman con otros filmes del género, y como esta interlocución conduce ellos a reverberar un imaginario de idealización de la prensa liberal que fue históricamente fomentado por el cine mismo - y que no necesariamente traduce los dilemas que el periodismo vivencia contemporáneamente.

Palabras clave: Cinema. Periodismo. Intertextualidad.

\section{Introdução}

Este artigo sustenta que, a despeito do realismo estético e narrativo que demarcam as duas principais correntes de produções cinematográficas estadunidenses sobre o mundo do trabalho dos jornalistas. Tais produções operariam menos como uma caixa de reverberação das transformações em curso nesse setor produtivo e mais como um agente histórico de celebração do jornalismo liberal e de reiteração de 
sua deontologia profissional - recorrendo, para tal, a uma trama intertextual que remete à própria filmografia do gênero.

Neste sentido, o argumento a ser desenvolvido neste texto se contrapõe parcialmente àquele proposto por Brian McNair (2010) na obra seminal Journalists in film: heroes and vilains. O livro em questão se ancora no silogismo de que, se o cinema é produto cultural capaz de acionar e reconfigurar certos imaginários em nossa sociedade, os filmes sobre o jornalismo seriam "registros do engajamento contínuo da sociedade com essa importante instituição cultural e política" (MCNAIR, 2010, p. 16, tradução nossa). ${ }^{2}$ Ademais, McNair (2010) ainda assevera, em tom entusiástico, ${ }^{3}$ que os cineastas que se dedicam à temática exercitariam a crítica da mídia (como um "quinto poder") ao ofertarem ao público narrativas sobre o que o jornalismo representa (ou deveria representar) em uma democracia liberal:

os cineastas, na medida em que suas obras são bem recebidas, constroem uma arena para o debate, frequentemente de alto nivel, e informam ao público e aos meios de comunicação [...] o que se espera dos jornalistas, nos indagando se essas expectativas estão sendo cumpridas. Eles contribuem para uma conversa pública em curso na qual o papel e as funções do jornalismo nunca estão à distância da zona de interesse e das preocupações legitimas [da sociedade] (MCNAIR, 2010, p. 19, tradução nossa). ${ }^{4}$

Os pressupostos teóricos assumidos na análise de fôlego de McNair, empreendida com 71 filmes lançados no Reino Unido entre 1997 e 2008, são também reiterados na literatura sobre representações cinematográficas do mundo do trabalho dos jornalistas (PAIVA, 2007: DROHAN, 2016; ROXO; GRUPILLI, 2019). 5 A influência dessa linha de raciocínio incide mesmo na crítica cinematográfica produzida por sites especializados em análise de mídia. A título de exemplo, quando Spotlight (2015), obra dirigida por Thomas McCarthy e premiada em 2016 com duas estatuetas no Oscar (incluindo a de melhor filme), fora lançada no Brasil, rapidamente foi saudada por comentaristas do Observatório da Imprensa (página que tem como proposta ser um fórum de opiniões) como um marco em realismo estético e narrativo por retratar com fidelidade o ethos jornalistico, privilegiando a atividade dos comunicadores às suas vidas pessoais (LINS DA SILVA, 2016); mas também por rememorar um passado glorioso do jornalismo investigativo, quando esse primava pelo interesse público (XEXÉO, 2016; COURI, 2016) e por servir, em última instância, à crítica da midia (DINES, 2016).

Visando problematizar tal pressuposto teórico no que tange à análise cinematográfica sobre o mundo do trabalho dos jornalistas, o presente estudo se debruça nas representações desses profissionais construidas em Spotlight e em 0 Abutre (2014) - ficção dirigida por Dan Gilroy e indicada ao Oscar de melhor roteiro original em 2015 (um ano antes de Spotlight ter sido agraciado com o prêmio máximo da academia) - explicitando a "trama intertextual" invocada pelas obras e a exemplaridade dos arquétipos mobilizados nas narrativas, além de indicar com quais outros filmes tais ficções estabelecem diálogo. Com essa investida, argumento que esses filmes (lançados a posteriori do levantamento proposto por McNair (2010)) não sofreram reformulações nos imaginários que acionam sobre a profissão a partir das transformações históricas no próprio campo jornalístico. Isto é, os longas-metragens em questão seriam menos influenciados pela "comunidade interpretativa" (ZELIZER, 1993) dos comunicadores do que por sucessivas iterações a filmes clássicos sobre o setor, reanimando, ex-

\footnotetext{
Do original: movies about journalism are documents of a society's ongoing engagement with this key cultural and political institution. Discretamente. McNair (2010) chega a reconhecer que tal filmografia comporia as fundações ideológicas da democracia liberal estadunidense em decorrência do fato de ser colorida pela nostalgia conservadora de celebração do status quo. Mas esta feição crítica em seu argumento é logo açodada pela ressalva de que as mitologias profissionais são também passiveis de serem questionadas pelo cinema (o que, segundo o autor, ocorreria nas produções cinematográficas por ele analisadas).

4 Do original: Film-makers, to the degree that their works are well received, construct an arena for debate, often very high profile, and inform the public and the media - or remind them, if they think they know already - of what is expected of journalists, and ask if those expectations are being met. They contribute to an ongoing public conversation within which the role and functions of journalism are never far away from that same public's zone of interest and legitimate concern.

5 Não obstante, Ehrlich (2006) e Lopes, Duarte e Vieira (2017) oferecem contrapontos à tese preponderante.
} 
plícita ou implicitamente, imaginários passados dos próprios cineastas sobre o que o jornalismo deveria (em sentido normativo) ser. Assim, mesmo em obras que aparentemente visam estimular debates tensionadores ao jornalismo comercial (como é o caso de O Abutre), no plano discursivo o mito da imprensa livre não seria questionado, mas sim tonificado - em franca dissonância aos impasses que vivencia esse modelo diante da crescente crise de credibilidade pública aos veículos de mídia.

Na seção seguinte são explicitados os critérios adotados para seleção do corpus e delineados os conceitos operadores do estudo. Na sequência, Spotlight e $O$ Abutre serão analisados a partir de seus componentes narrativos, das tramas intertextuais que mobilizam e dos discursos que legitimam. Por fim, a tese que defende a filmografia sobre o jornalismo como lugar de critica da mídia é revisitada e questionada à luz dos impasses que permeiam atualmente a profissão e do lugar ocupado pelo cinema internacional nessa conjuntura.

\section{Entre heróis e fora da lei}

Spotlight e O Abutre encarnam exemplarmente uma tradição no cinema hollywoodiano de contraposição entre imaginários oficiais e fora da lei das profissões liberais (EHRLICH, 2006). De um lado, ficções como Spotlight celebram as virtudes civicas do jornalismo (e mais especificamente do jornalismo investigativo), reforçando os principios éticos que os comunicadores deveriam atender para garantir ao cidadão o direito de ser informado sobre aquilo que concerne à coletividade (sobretudo em se tratando de conspirações tramadas às escondidas por poderosos). Ao fazer isso, no plano discursivo, tais filmes dramatizariam os ideais normativos do jornalismo, traduzindo-os nos termos da cultura popular (MCNAIR, 2010). De outro lado, em longas como O Abutre, questiona-se a corrosão desses principios por tabloides exclusivamente preocupados com os indices de audiência, repletos de trabalhadores que infringem frontalmente os códigos deontológicos do campo, manipulando ou fabricando fatos, des- respeitando a privacidade de fontes anônimas e reportando acontecimentos desprovidos de interesse público (EHRLICH, 2006).

Esses tropos estéticos e narrativos são clássicos em ficções que se centralizam no trabalho dos comunicadores, ou seja, que não apresentam repórteres e redações como elementos acessórios da trama (compondo o que se convencionou nomear como "gênero jornalístico" pela literatura acadêmica (NESS, 1997; BERGER, 2002; EHR$\mathrm{LICH}, 2004))$. Tanto em Spotlight quanto em $O$ Abutre, o mundo do trabalho é o objeto central do enredo, e por esta razão tais filmes fornecem "representações primárias" (MCNAIR, 2010) do jornalismo, pois os cineastas ensejam, com tais produções, estimular discussões sobre quais exigências normativas a profissão deveria ou não cumprir em um regime democrático. Nesse sentido, Spotlight e O Abutre, cada qual a seu modo, seriam as obras que melhor atualizariam contemporaneamente (dado o destaque obtido na mais aclamada cerimônia de premiação cinematográfica), sob um discurso de idealização ou condenação, os imaginários ficcionais sobre a atividade jornalistica.

Representações heroicas de repórteres, e especialmente do jornalismo investigativo, são por certo as mais reincidentes no cinema. Conforme McNair (2010), das 71 obras lançadas entre 1997 e 2008 sobre o jornalismo no Reino Unido, em 58 delas os comunicadores são retratados como profissionais que, a despeito de suas falhas, são atores sociais corajosos, persistentes e devotados ao trabalho, capazes de inspirar a confiança e empatia do público espectador. Tais obras aderem, frequentemente, à mitologia da imprensa liberal enquanto "cão de guarda" dos poderes instituídos em um governo democrático e fiscal dos desvios cometidos por grandes corporações, incluindo até mesmo as organizações de mídia. A ilustração mais paradigmática dessa corrente por certo é Todos os Homens do Presidente (1976) (EHRLICH, 2004; GHIGLIONE; SALTZMAN, 2005; MCNAIR, 2010), dirigida por Alan Pakula e protagonizada por um elenco estrelado (com Robert Redford e Dustin Hoffman interpretando Bob Woodward e Carl Ber- 
nstein, respectivamente) Tendo recebido quatro estatuetas do Oscar em 1977, o longa-metragem circulou pelo mundo difundido a mitologia de que o jornalismo investigativo seria o canal para revelação de escândalos políticos (uma vez que o caso Watergate, descortinado pelos repórteres do Washingston Post, levou à renúncia do Presidente Richard Nixon em 1974) (MCNAIR, 2010).

Apesar de menos numerosos no levantamento de McNair (2010), as figurações condenatórias de comunicadores são também usuais na história do cinema estadunidense. Como defende Matthew Ehrlich (2006, p. 502, tradução nossa), ao menos desde 1931, com o lançamento de Última Hora (1931), dirigido por Lewis Milestone, "a cultura popular tem apresentado retratos de 'maus jornalistas', os quais, de diferentes formas, contradizem a imagem do profissionalismo ético e firme que a imprensa tenta promover". 6 Embora nem todas essas representações inspirem necessariamente a reprovação moral da audiência, sobretudo quando os personagens têm o interesse público como meta (ainda que se valendo de meios escusos para tal) (EHRLICH, 2006), uma das mais famosas dentre elas é a do réptil (McNAIR, 2010), difundida em ficções que não necessariamente conquistaram bilheterias expressivas quando de seu lançamento ou foram premiadas em grandes festivais, mas que se consolidaram como clássicos posteriormente, a exemplo dos repórteres Chuck Tatum e Wayne Gale, de A Montanha dos Sete Abutres (1951) e Assassinos por Natureza (1994), respectivamente. Para McNair (2010, p. 144, tradução nossa), o réptil encarna o pior do jornalismo na midia comercial, e sua figuração em cena serve frequentemente para "alertar ao público de uma democracia que sua midia é, na pior das hipóteses, um predador correndo selvagem, e que ele - o público - é responsável por colocá-lo de volta em sua jaula".7

Em sintese, dentre os longas-metragens mais recentes que se centralizam no trabalho dos jornalistas, Spotlight e O Abutre são os mais exem- plares devido à projeção pública que obtiveram quando de seus lançamentos (alavancada pelas indicações ao Oscar) e por recorrerem aos dois principais imaginários que o cinema hollywoodiano mobiliza ao abordar profissões liberais. Ao analisá-los, pretende-se explorar "os elementos motivadores da ação do personagem jornalista, de modo a fazê-lo atender às exigências da ação filmica" (GOMES, 2013, p. 97) e em qual representação do mundo do trabalho essas ações ocorrem. Para além, busca-se desenredar as conexões que essas ficções tecem com outras produções do gênero que as antecederam, compondo uma trama intertextual. O conceito, proposto pela análise do discurso de linha francesa (FAIRCLOUGH, 2001), foi recentemente apropriado na averiguação dos paralelismos entre Spotlight e Todos os Homens do Presidente, possibilitando a identificação dos elementos constitutivos de ambas as narrativas e as relações explicitas e implícitas que a primeira obra mantém com a segunda (LOPES; DUARTE; VIEIRA, 2017). Por fim, quando se infere acerca do discurso filmico que estrutura tais produções, tem-se em mente os indicios de uma instância de enunciação que transparece nas narrativas (VANOYE; GOLIOT-LÉTÉ, 1994), mas que, antes do que nos apontar para as marcas de autoria, nos remetem aos tropos do próprio cinema que mais ou menos deliberadamente foram convocados quando da produção das obras.

\section{Um jornalismo cinematograficamente idealizado}

Como supramencionado, em artigo recente Fernanda Lopes, Maurício Duarte e Itala Vieira (2017) se dedicaram a evidenciar o patrimônio estético e narrativo de Todos os Homens do Presidente, posteriormente evocado em Spotlight. Os autores pontuam que, muito embora a trama do longa-metragem dirigido por Thomas McCarthy se passe no início dos anos 2000, a influência das 
tecnologias de informação e comunicação na prática jornalística quase não é retratada. Ả exceção da substituição de máquinas de escrever por computadores na redação do The Boston Globe, em termos estéticos a representação cinematográfica do mundo do trabalho dos jornalistas permanece inalterada de um filme a outro - a despeito da distância temporal que os aparta:

iluminação branca no teto de cor clara, mesas distribuidas sob a forma de estações de trabalho com seus ramais de telefone fixo, ritmo frenético de jornalistas digitando seus textos ou transitando com pressa, colegas de trabalho que vão às mesas uns dos outros, chefes que recebem os jornalistas em suas salas, mantendo a pose de autoridade (LOPES; DUARTE; VIEIRA, 2017, p. 5).

No caso de Todos os Homens do Presidente, a cenografia proposta pela equipe de produção visava ser verosímil à redação do Washington Post no início dos anos de 1970, mas no caso de Spotlight a referência para a construção do cenário era filmica antes que jornalística, pois livremente inspirada na infraestrutura construida para o longa-metragem de Alan Pakula (LOPES; DUARTE; VIEIRA, 2017). Para além, em ambas as obras a prática profissional tem como cenário principal locações exteriores, em uma clara alusão ao jornalista investigativo como o the leg man que realiza a apuração da pauta em contato direto e presencial com as fontes de informação - distintamente de um modelo redatorial (ou sentado) em que o profissional trata dados que não coletou ou entrevista fontes na própria redação via dispositivos eletrônicos (NEVEU, 2006).

Além disso, Spotlight espelha uma figuração contida dos seus protagonistas que já se fazia presente em Todos os Homens do Presidente, priorizando o trabalho em detrimento de quaisquer outras instâncias que poderiam atribuir mais camadas de personalidade aos personagens. No filme de Thomas McCarthy, a equipe destacada para a cobertura dos escândalos de pedofilia envolvendo padres acobertados pela Igreja Ca- tólica de Massachusetts por mais de 30 anos é composta pelos repórteres Michael Rezendes (Mark Ruffalo), Sasha Pfeiffer (Rachel McAdams), Matt Carroll (Brian d'Arcy James) e pelo editor Robby Robinson (Michael Keaton). Os jornalistas são retratados como profissionais resilientes (que persistem mesmo diante do emudecimento e ameaças das fontes) e que abdicam dos tempos livres em prol de uma entrega apaixonada à investigação a qual foram designados. Em mais de uma cena presenciamos os personagens (especialmente Mike Rezendes e Sasha Pfeiffer) indo à redação em momentos de descanso ou em dias de folga para darem prosseguimento ao caso por terem tido um insight que lhes permitiria avançar na apuração, ou ainda redigindo os textos tarde da noite (elemento também apontado na análise de Lopes, Duarte e Vieira (2017)). Ademais, em ambos os filmes, "a credibilidade do jornalista em falar dos fatos e o seu dever de neutralidade" (LOPES; DUARTE; VIEIRA, 2017, p. 17) são evocados como elementos intrinsecos ao ethos profissional.

Esta representação filmica do jornalismo como vocação fora construida imageticamente em Todos os Homens do Presidente por meio do minimalismo estético (decisão de Alan Pakula, que considerava que o caso Watergate era suficientemente instigante para dispensar o desenvolvimento emocional dos personagens da obra):

não há trilha sonora para adicionar atmosfera, e nem história de fundo para os dois jornalistas. Nós somente sabemos que Woodward estava no jornal por somente nove meses. enquanto que Bernstein estava há dezesseis meses "no ramo". Nós não vemos nada de suas vidas privadas, exceto uma cena do interior do apartamento de Woodward (MCNAIR, 2010, p. 61. tradução nossa). ${ }^{8}$

Em Spotlight, assim como em seu predecessor, a composição estética e narrativa de repórteres apaixonadamente empenhados em seu trabalho tem como propósito expor seu afinco em descortinar conspirações ocultas do grande público, protegendo os cidadãos dos poderosos que os

8 Do original: There is no musical soundtrack to add atmosphere, and no back story for the two journalists. We know only that Woodward has been on the paper for just nine months, while Bernstein has sixteen months "in the business". We see nothing of their private lives, except one interior of Woodward's apartment. 
exploram secretamente com o que é considerado o bem principal em uma esfera pública democrática: a informação (DROHAN, 2016). Nos minutos finais da trama, o personagem de Mark Ruffalo recebe a notícia de seu superior de que, por recomendação do editor-chefe, Martin Baron (Liev Schreiber), o escândalo investigado não seria publicado pelo The Boston Globe ate que fossem coletadas mais provas que indicassem uma conduta sistemática da Igreja Católica de acobertamento de casos de pedofilia. Sua reação impulsiva transmite ao espectador um anseio genuino de expor a verdade, denunciando os culpados pelos crimes:

Mike: Por que estamos hesitando?

[...]

Robby: Baron nos disse para conseguir o sistema. Precisamos de tudo. Essa é a única coisa que vai por um fim nisso.

Mike: Então vamos levar para o Ben e deixa-lo decidir.

Robby: Vamos levar para o Ben quando eu disser que é a hora.

Mike: É a hora, Robby! É a hora! Eles sabiam disso e deixaram acontecer com as crianças, certo? Poderia ter sido você, poderia ter sido eu. Poderia ter sido qualquer um de nós. Devemos eliminar esses vermes. Temos que mostrar às pessoas que ninguém pode ir longe com isso. Nem um padre ou um Cardeal, ou a droga de um Papa!9

Fato é que na filmografia sobre o jornalismo não foram somente Todos os Homens do Presidente e Spotlight que evocaram a imagem messiânica do trabalhador vocacionado ao seu ofício como forma de saudar, no plano discursivo, o papel da imprensa liberal enquanto "cão de guarda" da sociedade e fiscal dos poderes instituidos. Lançados no mesmo periodo histórico que a obra de Thomas McCarthy, tramas como Veronica Guerin (2003) e O Mensageiro (2014) também romantizam (e normatizam) a determinação irrestrita à atividade que por vezes leva um repórter a assumir riscos crescentes à sua vida em prol da verdade. No drama biográfico sobre a jornalista irlandesa homônima ao filme que, no início dos anos de 1990, conseguiu revelar as entranhas do tráfico de drogas em Dublin, o espectador acompanha como sua resiliência em investigar o caso a expos paulatinamente a graves riscos - que culminaram em sua morte (BROWN, 2008). Já na trama também biográfica dirigida por Michael Cuesta, Jeremy Renner interpreta Gary Webb, repórter que teve sua carreira manchada por ter sido desmentido após apurar um escândalo envolvendo a CIA à época do governo Ronald Reagan - que armava rebeldes na Nicarágua para contrabandear drogas para a Califórnia. Também nessas duas obras o arquétipo cinematográfico do trabalhador vocacionado assume o primeiro plano na narrativa, algo que Todos os Homens do Presidente propusera décadas antes na antológica cena em que Woodward e Bernstein vão ao encontro de sua fonte anônima, o Garganta Profunda, em uma garagem subterrânea deserta, sem ter a real ciência de quais perigos às suas vidas esse encontro soturno acarretaria (LOPES; DUARTE; VIEIRA, 2017).

Nesse sentido, ao recorrer a uma trama intertextual que mobiliza componentes estéticos e narrativos de outras obras para promover discursivamente ideais normativos sobre o jornalismo construidos pelo próprio cinema, tal qual reconhece McNair (2010, p. 59, tradução nossa), filmes como Spotlight poderiam ser lidos como manuais pedagógicos "fundamentais sobre a ideologia da democracia liberal, promovendo e alertando suas audiências, no idioma da cultura popular, porquê esse tipo de jornalismo é e deveria ser importante para elas, e porque está ameaçado e deve ser defendido".10 Não à toa tais obras são frequentemente biográficas (pois dramatizam eventos que poderiam ser tomados como manuais deontológicos de conduta) e remetem a outros momentos históricos - particularmente um passado glorioso em que o jornalismo cumprira com êxito seu papel, "publicizando os problemas políticos para o conjunto da sociedade" (ALBU-

9 Trecho transcrito de Spotlight (McCarthy, 2015).

10 Do original: core teaching texts of liberal democratic ideology, promoting, warning their audiences, in popular cultural idiom, why this kind of journalism is and should be important to them, how and why it is threatened, and why it must be defended. 
QUERQUE, 2000, p. 25) como preza a concepção mítica da imprensa liberal como "quarto poder".11

Similarmente a Spotlight, O Abutre também recorre a uma trama intertextual construída pela filmografia sobre o jornalismo que, nesse caso, serve ao propósito de denunciar a imoralidade de veículos rendidos à lógica estritamente financeira, além de problematizar os riscos que a sociedade corre (físicos e simbólicos) quando essa perversão aos principios jornalísticos (idealmente encarnados em obras como Spotlight) é levada a cabo.

A narrativa tem como protagonista Louis Bloom (Jake Gyllenhaal), cinegrafista amador freelancer que atua para um programa sensacionalista de um canal de TV local capturando e comercializando imagens viscerais de assassinatos e acidentes. Já no início da trama, a imoralidade de Bloom é retratada em uma cena noturna em que o vemos furtando fios de cobre, redes de arame e tampas de bueiro para vender para um construtor em Los Angeles. Na sequência, presenciamos também a falta de dignidade do protagonista, que se vale de um discurso inspirador típico ao ideário empreendedor (CASAQUI, 2017) para tentar uma vaga de emprego bajulando interlocutores que o desprezam. Na cena seguinte, no caminho de volta para casa, o crápula presencia um acidente que é o turning point do longa-metragem: junto aos policiais que socorrem acidentados de dentro de veículos em chamas, um operador de câmera freelancer grava a cena em primeira mão para comercializá-la com emissoras que exibem imagens de ocorrências noturnas em programas policialescos travestidos de telejornalismo. Vendo uma oportunidade de trabalho no setor, e despido de qualquer fagulha de caráter (como a narrativa já explicitara didaticamente nas primeiras cenas), o réptil de $O$ Abutre adquire uma câmera, um scanner da polícia e sai à noite à caça de desastres para filmar. A ausência de escrúpulos o permite capturar imagens de acidentados em close-up, deslocar cenas de crimes para conseguir enquadramentos mais dramáticos e até mesmo provocar ocorrências para obter material de vídeo.
A interlocutora de Louis Bloom no canal de notícias para o qual ele comercializa suas gravações com exclusividade, a montantes cada vez mais expressivos, a editora Nina (Rene Russo), é igualmente enquadrada na trama na mesma moldura perversa que o personagem principal: em sua primeira cena já nos deparamos com ela instruindo um editor de video a manipular uma gravação para torná-la mais dramática. Sintoma de uma midia entregue aos ditames do mercado, a editora nunca questiona a origem obscura das imagens de Bloom ou o grau cada vez mais extremo de violência presente nelas (o que causa espanto em seus colegas de redação em diversas ocasiões), mas somente o preço das fitas ou os eventuais riscos de ser processada por exibi-las. Os olhos de Nina estão dirigidos para os índices de audiência e para a sua permanência no emprego, e não para a deontologia jornalística, como somos lembrados insistentemente pela trama. Em verdade, a convivência (e subserviência) à mescla de linguagem motivacional e sociopatia de Louis Bloom só a tornam mais atraída pelas imagens grotescas que ele vende para o programa. Se no início da trama ela ensina para o aspirante a cinegrafista que a melhor descrição de seu noticiário seria "uma mulher aos berros correndo pela rua com a garganta cortada", ao final ela regozija com seu parceiro diante das cenas do assassinato do assistente de Bloom, vendidas para o programa como uma "peça de arte".

Embora o filme soe sintonizado a uma crítica da mídia contemporânea, em que oligopólios de mídia (primando por uma mentalidade financista) se afinam à lógica caça-cliques das redes, a estrutura estética e narrativa de $O$ Abutre e a discussão contemplada pelo filme remetem a uma filmografia do século passado. De partida, a trama de O Abutre pode ser interpretada, em linhas gerais, como uma adaptação atualizada de A testemunha ocular (1992), ficção dirigida por Howard Franklin que transcorre na Nova Iorque de 1942. O protagonista, Leo Barnstein (Joe Pesci), embora tenha o interesse público

11 Além de Spotlight, filmes igualmente recentes como Choque e Pavor (2017) e The Post: A Guerra Secreta (2017), também tratam a publicização de escândalos como função vital da imprensa. 
como finalidade última (distintamente de Louis Bloom), vale-se de métodos igualmente ilícitos e imorais para fotografar crimes e tragédias, como subornar agentes públicos e até mesmo manipular a cena de um assassinato para conseguir enquadramentos mais impactantes para as capas de tabloides sensacionalistas.

Não obstante, o casal insólito formado por Bloom e Nina no thriller é claramente inspirado na estética noir dos anos de 1940 e 1950, como nos informa McNair: "No filme noir um personagem masculino central é frequentemente alguém que cruza a linha entre o certo e o errado, o bem e o mal, frequentemente sob a influência de uma femme fatale sedutora. Essa transgressão provoca a sua própria queda" (McNAIR, 2010, p. 46, tradução nossa).12 Já no clássico (e supracitado) A Montanha dos Sete Abutres, Chuck Tatum (papel de Kirk Douglas) recebe apoio da esposa do mineiro Leo Mimosa, Lorraine Mimosa (interpretada por Jan Sterling) em sua farsa para construir um drama humano suficientemente atraente ao público, ávido por acompanhar em detalhes o resgate do homem preso em uma caverna. Também no filme de Billy Winder há uma voz da consciência a alertar o malfeitor de suas transgressões (nesse caso, o editor de Tatum, que pendurou na redação do tabloide onde o repórter trabalhava letreiros bordados com a frase "diga a verdade"). A única distinção mais saliente no enredo de A Montanha dos Sete Abutres em comparação a O Abutre é que, se no clássico dos anos de 1950 a vilania do personagem de Kirk Douglas é condenada com sua morte dramática na redação do jornal de Albuquerque após ter sido apunhalado pela amante, na trama de Dan Gilroy o protagonista não só sai ileso, mas também prospera no negócio que inaugurou, contratando novos funcionários e influenciando ainda mais negativamente a pauta do telejornalismo local.

Em ambos os filmes a yellow press ${ }^{13}$ é igualmente recriminada, seja por seu desdém pela ética jornalística (instrumentalizada para fins mercadológicos) ou pela cumplicidade do público com as histórias sensacionalistas de sofrimento humano. Por sua vez, esse discurso comum aos longas-metragens tem como primeiro antecedente histórico, conforme Loren Ghiglione e Joe Saltzman (2005), a trama de Sede de Escândalo (1931), em que o repórter inescrupuloso Isopod (interpretado por Boris Karloff), atendendo à ordem de seu editor para aumentar as vendas do tabloide em que trabalhava, desenterra um caso de assassinato encerrado há 20 anos, forjando imagens de uma das acusadas à época - que motivam o suicídio do casal vitimado pelo boato. Na cena final desse filme, a condenação ao jornalismo sensacionalista já se expressava de maneira análoga ao retratado em O Abutre: uma edição do tabloide noticiando a morte do casal vitimado pelos boatos é coberta com lama e varrida das ruas.

Contudo, nas entrelinhas dessa ácida crítica aos desvios éticos da imprensa são reafirmados os mesmos ideais normativos que o cinema estadunidense historicamente credita ao jornalismo, seja retratando heróis como a equipe do The Boston Globe ou crápulas como Louis Bloom: se exercido conforme os códigos deontológicos e primando pelo interesse público, o jornalismo é pilar da democracia. Conforme Ehrlich (2005, p. 106, tradução nossa), tais obras ratificam o status quo na medida em que "reafirmam que as pessoas podem fazer a diferença, os erros podem ser corrigidos e o sistema pode funcionar, tudo com a ajuda de uma imprensa fundada na autoridade profissional, na independência e em empresas livres". ${ }^{14}$ Isto é, a critica aparentemente cáustica de $O$ Abutre não atinge os imaginários mais arraigados do jornalismo estadunidense e muito menos questiona veículos como o que Bloom atua de uma perspectiva mais estrutural (mobilizando um debate sobre a regulamentação dos meios ou sobre a concentração de propriedade nas mãos de conglomerados de mídia). Não é

\footnotetext{
12 Do original: In film noir the central male character is someone who crosses the line between right and wrong. good and evil, often under the influence of an alluring femme fatale. This transgression brings about his own downfall.

13 A expressão, de cunho pejorativo, surgiu no final do século XIX para tipificar o tipo de jornalismo exercido pelo New York World e pelo New York Journal quando estes travaram uma guerra de concorrência nos EUA.

14 Do original: Journalism movies regularly assert that people can make a difference, wrongs can be corrected, and the system can work, all with the help of a press founded on professional authority, independence, and free enterprise.
} 
fortuito, portanto, que em determinado momento do longa-metragem tenha ocorrido o seguinte diálogo entre a editora Nina (preocupada com os riscos legais de veicular imagens explícitas de um assassinato, coletadas por Bloom antes da chegada da polícia) e um repórter da KWLA News:

Repórter: Jornalistica e eticamente falando ultrapassariamos todas as regras de emissão de conteúdo.

Nina: Você tem visto as audiências? ${ }^{15}$

Neste sentido, a reflexão proposta pelo filme se circunscreve a aspectos que o cinema já tratara desde a primeira metade do século XX: a rendição da imprensa aos apetites mais vis do público, a responsabilização moral de uma sociedade que banaliza a dor alheia e a imoralidade de trabalhadores que, despidos de qualquer dignidade profissional, alimentam o apetite censurável da audiência.

\section{Considerações finais}

Nos últimos anos, o jornalismo tem vivenciado um paulatino decréscimo de credibilidade pública. Em março de 2019, a Edelman Trust Barometer (2019) publicou seu relatório anual em que aponta que o percentual de confiança na imprensa entre o público geral em termos globais é de $47 \%$, o mais diminuto entre as instituições avaliadas. Além disso, somente $36 \%$ da população considera os jornalistas como fontes confiáveis. Esse cenário de crédito reduzido nas organizações de mídia decorre, entre vários fatores, das reestruturações nas empresas de comunicação, que se intensificaram ao longo dos anos 2000 (com enxugamento de postos, aglutinação de funções e extensão das jornadas de trabalho) e do volume torrencial de boatos que circula em ambiente online (o levantamento destaca que 73\% da população mundial teme os impactos nocivos das fake news na esfera pública).

No que diz respeito especificamente ao jornalismo estadunidense, em 2012 o Tow Center for Digital Journalism da Columbia Journalism School publicou um relatório assinado por Chris
Anderson, Emily Bell e Clay Shirky (2013) em que são apontadas diversas razões para a crise hoje enfrentada pelas organizações de mídia: transição deficitária do modelo de financiamento tradicional do imprenso para o digital (modelo subsidiado via receitas de anúncios publicitários); inserção de novos atores no ecossistema jornalístico (sejam eles canais de mídia independente ou blogs alimentados por cidadãos comuns), quantificação da audiência via metrificação do tráfego digital, concentração de capital nos grandes conglomerados de mídia, entre outros aspectos - todos eles a léguas de pautarem a produção cinematográfica estadunidense sobre o mundo do trabalho dos jornalistas. Isto é, as questões colocadas por filmes como O Abutre ou Spotlight não se alinham às problemáticas que de fato permeiam as reflexões mais contemporâneas sobre o jornalismo, tal qual proposto por McNair (2010) em sua obra seminal sobre o tema ao sugerir o cinema como um "quinto poder" apto a edificar uma arena pública de discussão sobre o papel da mídia nas democracias modernas.

A filmografia analisada neste artigo constrói um discurso de aclamação da imprensa liberal como instrumento de salvaguarda do cidadão comum, seja difundindo suas mais respeitadas conquistas via dramas biográficos como Spotlight, seja advertindo para os perigos de desatenção aos códigos deontológicos e de rendição irrestrita à lógica mercadológica, como a trama de O Abutre ilustra. Em ambos os casos, são reiterados imaginários sobre a profissão construidos décadas passadas pelo próprio cinema (em uma trama intertextual finamente articulada) - muito embora a filmografia sobre o mundo do trabalho dos jornalistas historicamente reivindique certo realismo estético e narrativo.

Por essa razão, é crucial revisar o pressuposto de McNair (2010), encampado por diversos estudiosos do cinema, de que as produções cinematográficas que se centralizam na imprensa são terreno fértil para discussão sobre os rumos da profissão. Adotar este discurso implica em reiterar

15 Trecho transcrito de O Abutre (GILROY, 2014). 
um imaginário sobre o jornalismo que atende expectativas do próprio cinema. Isto é, não se deve pressupor que os longas-metragens que se debruçam no mundo do trabalho dos jornalistas são necessariamente antenados ao "espírito do tempo" ou afinados à literatura acadêmica. Como o próprio McNair (2010, p. 27, tradução nossa) reconhece, não é dever do cinema de ficção ser impreterivelmente "realista" (mesmo em dramas biográficos), já que, "para a maioria dos jornalistas, de fato, a realidade da vida profissional é menos excitante do que a sua representação filmica" ${ }^{16}$ Mas por outro lado, antes que tomar a filmografia estadunidense sobre o jornalismo como sintomática dos dilemas que permeiam a profissão, deveriamos analisá-la como um repositório de expectativas que o cinema hollywoodiano historicamente depositou sobre a imprensa.

\section{Referências}

ALBUQUERQUE, Afonso. Um outro quarto poder: jornalismo e responsabilidade política no Brasil. Contracampo, Rio de Janeiro, v. 4, p. 23-57, 2000.

ANDERSON, Chris; BELL, Emily; SHIRKY, Clay. Jornalismo pós-industrial: adaptação aos novos tempos. Revista de Jornalismo da ESPM, São Paulo, n. 5, p. 30-89, 2013.

BERGER, Christa (org.). Jornalismo no Cinema: filmografia e comentários. Porto Alegre: Editora da UFRGS, 2002.

BROWN, Robrter. Crime reporting: Veronica Guerin. In: GOOD, Howard. (org.). Journalism ethics goes to the movies. Maryland: Rowman \& Littlefield Publishers, Inc., 2008. p. 125-136.

CASAQUI, Vander. Abordagem crítica da cultura da inspiração: produção de narrativas e o ideário da sociedade empreendedora. E-Compós, [S. l.], v. 20, n. 2 , p. 1-18, 2017. https://doi.org/10.30962/ec.v20i2.1355

COURI, Norma. Spotlight: mais que uma carta de amor ao jornalismo. Observatório da Imprensa. 2016. Disponivel em: http://observatoriodaimprensa.com.br/ cinema/spotlight-mais-que-uma-carta-de-amor-ao-jornalismo/Acesso em 5 jul. 2019.

DINES, Alberto. Resenha das resenhas: Brasil parece Boston. Observatório da Imprensa. 2016. Disponivel em: http://observatoriodaimprensa.com.br/imprensa-em-questao/resenha-das-resenhas-brasil-parece-boston/Acesso em 5. Jul. 2019.
DROHAN, Michele. Spotlight and Investigative Journalism: How the Film Reinforces the Essential Role of a Free, Professional Press in a Democracy. The Serials Librarian, [S. l.], v. 71, n. 3-4, p. 212-220, 2016. https:// doi.org/10.1080/0361526X.2016.1237403

EDELMAN TRUST BAROMETER. 2019 Global Report. Edelman Inteligence, 2019. Disponivel em: https://WWW. edelman.com/trust-barometer. Acesso em 11 nov. 2019.

EHRLICH, Matthew. Journalism in the Movies. Urbana University of Illinois, 2004.

EHRLICH, Matthew. Shattered Glass, Movies, and the Free Press Myth. Journal of Communication Inquiry, [S. l.], v. 29, n. 2, p.103-118, 2005. https://doi. org/10.1177/0196859904272741

EHRLICH, Matthew. Facts, truth, and bad journalists in the movies. Journalism, [S. l.], v. 7. n. 4, p.501-519, 2006. https://doi.org/10.1177/1464884906068364

FAIRCLOUGH, Norman. Discurso e mudança social. Brasilia: Editora Univ. de Brasilia, 2001

GHIGLIONE, Loren; SALTZMAN, Joe. Fact or fiction: Hollywood looks at the News. Images of the Journalist in Popular Culture Journal. 2005. Disponivel em:

https://www.ijpc.org/uploads/files/hollywoodlooksatthenews2.pdf. Acesso em: 5. jul. 2019.

GOMES, Vitor. O jornalista enquanto herói: uma proposta para análise das representações do jornalismo no cinema. Estudos em Jornalismo e Mídia, Florianópolis, v. 10, n. 1, p. 85-102, 2013. https://doi.org/10.5007/ 1984-6924.2013v10n1p85

LINS DA SILVA, Carlos. Jornalismo sem glamour na telona. Observatório da Imprensa. 2016. Disponivel em: http://observatoriodaimprensa.com.br/cinema/ jornalismo-sem-glamour-na-telona/ Acesso em: 5. jul. 2019.

LOPES, Fernanda; DUARTE, Maurício; VIEIRA, Itala. Representações cinematográficas do jornalismo investigativo em Todos os homens do presidente (1976) e Spotlight (2015). FAMECOS, Porto Alegre, v. 24, n. 3, p.1-20, 2017. https://doi.org/10.15448/1980-3729.2017.3.26904

McNAIR, Brian. Journalists in film: heroes and villains. Edinburgh: Edinburgh University Press, 2010.

NESS, Richard. From Headline Hunter to Superman: a journalism filmography. Lanham: Scarecrow, 1997.

NEVEU, Erik. Sociologia do jornalismo. São Paulo: Edições Loyola, 2006.

O ABUTRE. Direção de Dan Gilroy. EUA: Open Road Films, 2014. 1 DVD (117 min), son., color., digital.

PAIVA, Cláudio. Os jornalistas, a televisão e outras mídias no cinema: um estudo de ética e representação na arte cinematográfica. FAMECOS, Porto Alegre, n. 32, p. 89-96, 2007. https://doi.org/10.15448/1980372. 2007.32 .3420 
ROCCHI, James. Interview: 'Nightcrawler' Director Dan Gilroy Talks Jake Gyllenhaal, Robert Elswit \& Sociopaths. IndieWire. 2014. Disponivel em: https://www.indiewire. com/2014/10/interview-nightcrawler-director-dan- gilroy-talks-jake-gyllenhaal-robert-elswit-sociopaths-270834/. Acesso em: 18. jul. 2020.

ROXO, Marco; GRUPILLO, Aline. Produção de imagem e autoridade jornalística: reflexões sobre jornalismo amador a partir de O Abutre. Contemporânea, Salvador, v. 17, n. 1, p. 99-121, 2019

SPOTLIGHT: Segredos revelados. Direção de Tom McCarthy. EUA: Open Road Films, 2015. 1 DVD (129 min), son., color., digital.

XEXÉO, Artur. Um filme sobre o bom jornalismo. 0 Globo. 2016. Disponivel em: https://oglobo.globo.com/ cultura/um-filme-sobre-bom-jornalismo-18443149. Acesso em: 5 jul. 2019.

VANOYE, Francis; GOLIOT-LÉTÉ, Anne. Ensaio sobre a análise filmica. Campinas: Papirus, 1994.

ZELIZER, Barbie. Journalists as interpretative communities. Critical Studies in Mass Communication, [S. l.], v. 10, n. 3, p. 219-237, 1993. https://doi. org/10.1080/15295039309366865

\section{Thales Vilela Lelo}

Doutor pelo Programa de Pós-Graduação em Ciências Sociais da Universidade Estadual de Campinas (UNICAMP), em Campinas, SP, Brasil; pesquisador de pós-doutorado no Departamento de Comunicações e Artes da Universidade de São Paulo (ECA-USP), em São Paulo, SP, Brasil, com bolsa da Fundação de Amparo à Pesquisa do Estado de São Paulo (FAPESP), em São Paulo, SP, Brasil.

\section{Endereço para correspondência}

Thales Vilela Lelo

Universidade de São Paulo (USP)

Escola de Comunicações e Artes

Av. Professor Lúcio Martins Rodrigues, 443

Butantã, 05508020

São Paulo, SP, Brasil 